\title{
Aspects of Corporate Governance in Developing Countries
}

\author{
Dr. MUHAMMAD MAJID MAHMOOD BAGRAM \\ Associate Professor, Department of Business Administration, \\ Allama Iqbal Open University, Islamabad, Pakistan. \\ Email: bagram@hotmail.com
}

\begin{abstract}
AKBAR ABBAS BANGASH
Quaid-i-Azam School of Management Sciences, Quaid-i-Azam University Islamabad, Pakistan.
\end{abstract}

\section{ZARA KIRAN}

Junior Lecturer, MUST Business School,

Mirpur University of Science \& Technology (MUST), Mirpur, AJK, Pakistan.

\begin{abstract}
This research article throws light on the impacts of Corporate Governance in the developing countries particularly to Pakistan, Mexico, Brazil and Bangladesh. The paper starts with discussions on how and when there is an alteration in different features of company administration during the practice of financial advancing in Mexico. It encompasses ultimately the impact of transforms in the replica of business control regarding the expansion of the state e.g. enlargement in purchaser commodities in favour of central group buyers, growth revelation through home firms, fewer help in favour of community public schemes etc. The authors of this research article assert that problems of governance in Bangladesh are at the helm of affairs of its economy. We observed the data regarding governance of Bangladesh of period 1996-2004 and analysed these various governance dimensions out of the aforesaid economic progress analysis the key dimensions have been divulged. These are political governance, institution dimensions and technology dimensions. The political governance in Bangladesh has been paralysed from 1998 to 2004 . When the performance of governance in Bangladesh become functional it had positively affected the economy. We cannot say the importance of company authority within growing kingdoms. The commercial domination might include a slightly different system than prevalent in the European countries and North America due to insufficient infrastructure and destroy governmental policy interventionism. We also throw light on important features of Brazilian firm's changes after the application for communal power exercises. After making a deliberation on the implementation of joint supremacy in Brazil, Mexico, and Bangladesh and subsequently we have emphasized the impact of Corporate Governance and proper growth in Pakistan. The relationship between good governance and proper growth is proportional generally. Having studied different scenarios of the countries under remonstration, the writers have reached the conclusion that good governance is an essential component for upgrading the economies of developing countries because of these reasons it may be said that high-quality control leads towards a country obtain sky-scraping and frequent monetary increase through establishment of congenial environment for savings and investment, entrepreneurship, yielding implement upon manufacturers, generating constancy among marketplace, expansion in souks though elimination of hurdles/barriers towards inner job and progress over the competitors.
\end{abstract}

Keywords: Business Control, Economic Development and Proper Growth. 


\section{Introduction}

In the era of $21^{\text {st }}$ century, the corporate governance has obtained remarkable position for large and medium organizations. Critical risks become hurdles without corporate governance strategy while results become significant better for those organizations which has governance strategy. There is need to know the proper definition of corporate governance and decision making of directors. Corporate governance is the mechanism and system of directing and controlling the business corporations. According to criteria defined by OCED the structure of corporate governance postulates the distribution of responsibilities rights between different stakeholders including managers and shareholders etc. It is also useful for better decision makings on corporate affairs and dealings. This also provides guidance and support to achieve business objectives and goals. Different aspects of corporate governance in developing countries particularly to Pakistan, Mexico, Brazil and Bangladesh are seen by recognizing the above mentioned significance of corporate governance.

The concern and issue of governance has obtained importance over the last 2 decades and has become vital element for economic development, s policies. To influence economic growth corporate governance, play a vital role. Evidences suggest that lack of good governance creates hurdles in form of poverty and un equal distribution. It also creates bad impact of on growth and investment. If there is problem in good governance all efforts are useless to expand and raise infrastructure and investments and raise educational standards as well. All developing countries are considered as low level human development as there is unequal distribution which cause poverty, low educational standards and zero growth in economy. Poverty traps are created which are difficult to tackle to all these end results and outcomes. The reforms and developments should be made by state of affairs to achieve economic growth. Good governance is back bone of any country to achieve sustainable economic growth by expanding its trade beyond the national borders.

Has good governance created pro-poor growth? Since 1990 good governance has crucial stage in development rational \& practice. International development community is also interested and paying attention for good governance they are also interested for financial aid with the condition of good policy environment. To overcome the bad governance there is need of political strength and strong institutions by the governments.

The focus on restructuring economies to obtain high rates of economic growth is always appreciated as it causes low poverty and improves life style. The link between high economic growth and low poverty rate is no long lasting but it is directly proportional with each other as economic growth increases poverty leads to reduction. Practical implications reveal that economic growth impacts substantially on poverty rate even in same country. So main focus of countries should be on economic reforms that causes economic growth linked with substantial gains to pro- poor growth. The pro-poor growth promotion is now agenda of international stakeholders and donors.

\section{Rationale of the study}

During last 3 decades' substantial changes \& improvements has been happen and occurred in the corporate world. Because of transformation of most of companies in public limited companies the transfer in ownership was apparently observed. So team of professional and skilled work force was mandatory to operate and manage the giant organizations in well and effective way to increase and maximize the wealth of stakeholders. Ownership was deviated into sponsorship, international investor's government institutions and general public as well. Many stakeholders at the other end are the part of corporate body and they result in complications to run the corporations. The ownership structure and good corporate governance always leads to firm's performance. Many researchers have put their contributions to highlight the several issues of corporate governance but only few studies reveled on the issue of this topic which is not sufficient to fulfil the needs of this issue. For this reason, there is much rationale to find out the existing scenario 
corporate governance in developing countries of our sample countries Pakistan, Bangladesh, Brazil and Mexico

\section{Objectives of the Study}

The objectives of this present research reflect and determine the practical and empirical implications of analysis of environment of corporate governance and it provide understanding of corporate governance in our sample countries, to analyse the constraints to good corporate governance and to know the culture in these developing and emerging countries.

\section{Limitations of the Study}

There are certain limitations of the present research. Firstly, there is limited time available for the conduct of this research study. The dimensions of corporate governance are so vast. Secondly there are number of hurdles while collecting data from the selected developing countries.

\section{Literature Review}

A framework was developed for measuring and evaluating governance performance and relating this performance with poverty trends by Ahmed (2001) with his analysis on political economy aspects of poverty reduction in South Asia. He also analysed that good governance is major and significant problem in South Asia with direct association of poverty reduction. He explained that good governance is mandatory to reduce poverty rate in any country. Chatterjee, et al. (2006) raised the remarkable question that why in Bangladesh changes in economy not happened since 1990'.? Their research concluded that week political and economic decisions, weak institutions and unequal distribution of wealth and other resources always result in low and poor economic growth and this is hurdle in pro-poor growth.

Kaufmann and Aart (2002) gave the suggestions that good quality of governance and per capita income are positively correlated beyond the borders. These empirical results revealed that a strategy could be made to spreading this correlation in to 2 parts. $1^{\text {st }}$ is higher per capita from better governance, $2^{\text {nd }}$ a poor and weak causal effect running from in other direction from governance to per capita income. Empirical results of their study provide evidences that higher income always support proper improvements in governance.

Ten points theory of Kimnenyi (2005), the theory of pro-poor, growth should be adjusted and incorporated all economic reforms that are interested to generate pro-poor growth. These 10 points and principles tinted the worth of understanding poverty, their living style and economic activities, abilities and capabilities and other constraints that hinder their mutual participation in market place and also indebtedness of linkage with regions and sectors. He has point that until, there are no significant changes, in institution pro-poor reforms cannot have intended impacts. To support social and economic development process these reforms are mandatory.

A framework of link between several aspects of pro-poor growth and governance was developed by Resnik \& Regina (2006). With the help of this framework they have viewed empirical cross countries studies that included in it measure of governance as IV and pay focus on DV in at least 2-3 dimensions of pro-poor growth, poverty, growth and inequality. This link shows political stability of any country and rules of law are associated with growth but results are mixed about poverty reduction.

In light of Mexican law, corporate governance is the obligation of more than one director who may or may not be executives of the corporation. Where there are more than 2 directors, (a board of directors) is fashioned(LGSM,2001,Art.142 and 143).Though, since Mexican companies are family generated (whether they remain public or private companies).employing directors to the board is mainly a family substance or matter(La Porta et al.,1999).According to (Stewart,1993; Jensen 1989)in which Mexican patterns are 
contracted with international patterns in which organizations tend to combine functions and responsibilities of CEO,s and BODs.(Stewart 1992) also explained global corporate boards are involved in recruiting, hiring, firing and compensating them. But Mexican law is subject to hiring and firing of staff it has no concerns regarding compensations LGSM, Art.145. So Mexican stock exchange and Mexican law represent that boards should make it sure to align the vision approaches with management for effectiveness and efficiency (Consejo Coordinador Empresarial, 1999). In Mexico control on market is quite weak.

Vigorous environment is created by deregulations, trade liberalization and globalization for better management system in Mexican companies and it is demand of global investors that there should be good corporate governance and it has helped the Mexican corporate governance as well since last 15 years of this century. Globalization bounces companies' entrée to financial technology that empowers them to increase funds using new securities and to manage their risks more effectively (Rene .M Stulz 2013). The Mexican equitant of the U.S. Securities and Exchange Commission is the National Banking and Securities, issued "circular 11-29 in 1997" required to disclose director information for new issues of securities attached to the prospectus of listed companies. In 1999, Consejo Coordinator Empresarial mentioned in his research that particular requirements comprise reveals of names and numbers resumes and family relationships of board members with others board members. In 1999, the publication of the code of Best Corporate Practices by the Sock Exchange of Mexican culminated these pressures. On the other side, the code mentioned the significant position of hiring sovereign directors (20 percent of members of board, at least), disclosed current position and nature of directors and send particular information to directors in advance of meetings.

As one of its core responsibilities of the board's strategic function are also highlighted by Code. In their annual reports, the code inspires the listed companies to reveal the degree of devotion to such type of practices. In 1999, on an annual basis CNBV is required that all listed firms in the market of stock reveal their compliances with defined code as of January 01, 2001.

After that we analysed the Corporate Governance issues in Brazil. In 1998, the brief analytic study of corporate governance substantiates the statement of La Porta et al. in Brazil. As well in most countries, there are certain key issues of limitations of corporate governance particularly when talking about the rights of minority shareholders in these developing countries. In ADR Market, it demonstrated that, the efficient and effective organizations may move towards those legal systems that also do not protect the rights of minority shareholders. After that in Pakistan, the researchers analysed the interaction between governance and pro-poor growth. In 2004, Kraay conducted a study and found that change in income due to growth in average income impacts the 60 to 95 percentage of poverty while in the short run, change in income distribution are relatively more important. Researcher also examined that directness to the international trade are significant positively correlated with growth and correlated poverty reducing shifts in incomes while accountability and rule of law are both has a significant positive correlation with distributional changes and growth. For the enhancement of the stakeholder's long term value in the environment of business robust governance played a very crucial role. The new information age technology determined, robust corporate governance is more effective instead worthy business practice. Moreover, enhancement of managerial quality stewardship and ultimately leads capital markets are more effective and efficient and is recently demand from investors and others for greater accountability from corporate boards and audit committees. The positive corporate governance developed through the amendment of corporate control instruments and mechanism was very complex and complicated job due to the underdeveloped institutional infrastructure transition economies like Bangladesh, the state and financial sectors of complex corporate ownership between, feeble legal and judicial systematic structure and rare human possessions competences.

When we talk about most of the organizations in Bangladesh, the good corporate governance practices are missing from most of them. On the other hand, in most cases, efforts to improve good corporate governance practices are mostly discouraged and employees do not take it positively. There is another major challenge here is Bangladeshi organizations, it is the poor structural systems of organizations. It also 
results in declining performance in most of the cases. There are no major efforts to improve this declining situation in most of the organizations. Most of the employees serving in organizations do not adopt good corporate governance practices as their responsibility.

In Bangladesh, social media, print and electronic media, investors and shareholders may help improve this declining situation with reference to adoption of good corporate governance practices. But another major issue is lack of awareness regarding rights and responsibilities. These concerned organizations do not have the true awareness of their rights and responsibilities that also result in poor performance of organizations in Bangladesh. Shareholders associated with public are not planed and organized under a common platform to claim good corporate governance.

There is another major challenge here in Bangladesh, there is no joint platform for the institutional shareholders. Due to this major drawback, there are no joint efforts and there is no focus in most of the cases. In most advanced countries like United States of America and United Kingdom, there are number of such platforms for institutional shareholders. The Bangladesh capital market is not able to give strength to corporate governance still. The inclusive performance measures contributions and shaky valuations are more on the waning side. The stock market disgraces in 1996 has completely decrease share holder selfreliance in the stock market. But only recently the effect of the shock started receding. Besides, there are no bonds, fixed income or debt instruments in the groups for implementing corporate governance moralities. In case of leading non-banking listed companies in Bangladesh, the board is seriously controlled by sponsor stockholders who normally belong to a single family. The boards are aggressively intricate in administration.

The Chairman and the CEO would be isolated and the responsibility should be clearly identified. But most often the same person holds the same post. Normally the most senior member of the family holds the two posts according to seniority in the family relationship and juniors are director. Most autonomous directors characterize current or previous, government bureaucrats or administrators or sometimes university teachers who are skilled in the field of accounts and finance. They are selected directors to support company in receiving licenses or as repayment for former errands when he was govt. officer. Very often they don't act as an advocate for minority shareholders. The understanding of company operations is very low by number of shareholders with sufficient skills and knowledge. But general shareholders don't pay their attentions like performance, business plans, and future strategies of companies. In reality there is little and low awareness about responsibilities and rights. Sometimes, people ignore the whole recruitment process and compensations plans accordingly. Individuals are recruiting and discounting the legal rules \& procedure, even the wages and remuneration structure are not always justified\& vindicated according to their competence, knowledge, abilities skills and responsibility or job attachment.

Most family business appoints relatives who have no skill, knowledge's and abilities regarding job. Sometimes, upgradation and promotion is given avoiding occupation rule and codes \&conducts. So, unskilled and ineligible workforce and manpower runs the corporation which may sometimes lead low and poor performance of the entire company or business. For example: Current turbulent situation by the labour in Garments industry is the outcome and result of weak corporate governance practice within the firm. Their salary and wages, promotion etc. are not justified.

\section{Methodology}

This study is based on of literature, survey and secondary data and information. The data is gathered after going through different sources like international conferences, Journal papers on Corporate Governance in developing countries CG in developing countries and in same way newspaper \& articles have been surveyed for contribution in this study. 


\section{Theoretical Framework}

Independent Variables

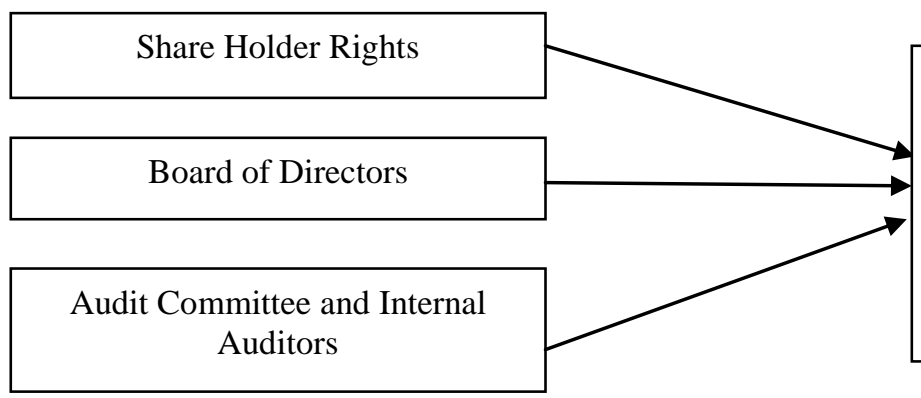

Dependent Variable

Good Corporate Governance:

1) Disclosure to Investors

2) Firm Corporate Culture

3) Ownership Parity

The structure of this research article stands on reason and outcome association. So this source and consequence affiliation is being reviewed during the impact of autonomous variables (Shareholder rights, panel of Directors, inspection team and internal auditors, disclosure to investors, Firm Corporate Culture and Ownership parity upon the dependent variable good corporate governance. To analyse the above cause and effect relation, the above model is established. If the indicators of independent variables are performing properly then it means good corporate governance practices are Appling on the country or corporation.

\section{Research Design}

Mostly in secondary based information researches, available data is analysed and relay on its reliability and accuracy during the research process. We collected our data for this research article from different websites, libraries and articles to complete our research.

\section{Sample size}

The sample size of our study is four developing countries and different issues of these countries regarding corporate governance and its influence on economic development and progress.

\section{Data Collection and Analysis}

By comparing Corporate Governance practices in different developing countries was done to determine how the different elements regarding your economy, company performance, board of directors etc. are going to be happen. The examined outcomes are complex for the team who are associated with the decision making process. Moreover, outcomes were meaningful for easily comprehensible.

\section{Conclusion}

After taking the different scenarios of our sample developing countries, we reached on this conclusion that at present the requirement for reinforcement of the business authority in developing countries arises with a global claim for a wide-ranging and obvious corporate world system.

Many researchers in their research has viewed corporate governance as control mechanism internally or externally that provide a good corporate behavioural process. This process has given values to shareholders transparently. It is dilemma in developing countries that cannot develop their institutions properly, bad market behaviour and legal enforcement agencies also cause in failure of good corporate governance. Corporate Governance is not just name of good management but is name of transparent administration 
(Sekhar Muni Amba 2014). A huge number of companies in developing countries do not pay attention to follow rules of business designed by stock exchange this results in bad governance. But this is hopeful that there is no serious scandal in respect of corporate governance in developing countries. It is seen that in many zones, system and scheme did not deliver adequate motivations and inspirations in terms of lawful \&legal, institutional or economic, for the shareholders to motivate, arouse, enforce and inspire worthy corporate governance. As a result, they added, there were hardly any rewards for the companies that founded virtuous corporate governance practices and no penalties and disadvantages for failing to do so. Stock Exchanges of sample countries are going to integrate corporate governance ethics in the slope \& gradient of the stock exchange to settle down a competitive environment in the capital marketplace. However, the Securities and Exchange Commission informed certain further sceneries for the public listed companies with any stock exchange in country, on mandatory basis, in order to improve corporate governance in the curiosity of investors and the capital market.

\section{Recommendations}

1. It is suggested that the capacity of self-sufficient administrative in a panel should be additional than the executive directors.

2. The recommendation has been made that the review team participants should consist of selfdetermining elements and have charge above monetary issues of the corporation.

3. It has been proposed that the management may constitute a procedure to examine that the appropriate principles of company governance are utilizing in the corporations in its genuine strength.

4. The administration might be introducing various instruction modules for the suitable coaching to management \& directors of the organization and also facilitate them regarding the concept of company domination for the better control over the corporation issues.

\section{References}

Ahmed, S. (2001) Poverty Reduction and Governance in South Asia. Mahbubul Hag Human Development Review 1:1.

Amba, S. M. (2014). Corporate governance and firms' financial performance, Journal of Academic and Business Ethics, 8, 1.

Anwer, Talat (2005) Long Term Changes in Income Distribution in Pakistan: Evidence Based on Consistent Series of Estimates. Centre for Research on Poverty Reduction and Income Distribution. (Discussion Paper Series No.03.)

Anwer, Talat (2006) Measurement of Absolute Poverty and Governance in Pakistan:1998-99 and 2004-05. Paper presented at 22nd Annual General Meeting and Conferences of Pakistan Society of Development Economists.

Asian Development Bank (1995) Governance: Sound Development Management. Manila: Asian Development Bank.

Chatterjee, Bipul. (2006) Institutions and Pro-Poor Growth in Bangladesh. Institute of Pro-Poor Growth, UK. (Working Paper Series No.2.)

Chong, A and M. Gradstien (2004) Inequality and Institutions. Inter-American Development Bank, New York. (Research Department Working Paper No. 506).

Christiansen, L., L. Demery, and S. Paternostro (2003) Macro and Micro Perspectives of Growth and Poverty in Africa. The Work Bank Economic Review 17,317-347.

Consejo Coordinador Empresarial: 1999, C6digo de mejorespracticascorporativas (Consejo Coordinador Empresarial, Mexico, D.F.).

Dollar, D. and A. Kraay (2002) Growth is Good for the Poor. Journal of Economic Growth 7,195225.

Hassan, Mian Tayyab (2002) Governance and Poverty in Pakistan. Pakistan Institute of Development Economics. (MIMAP Technical Paper No.13.)

Kakwani, N. and E. Pernia (2000) What is Pro-Poor Growth? Asian Development Review18:1. 
Kaufmann, D. and A. Kraay (2002) Growth without Governance. Washington, DC, World Bank. (World Bank Policy Research Working Paper No. 2928.)

Kaufmann, D., A. Kraay, and M. Mastruzzi (2005) Governance Matters IV: Governance Indicators for 1996-2004. World Bank, Washington, DC.

Kimnenyi, Mwangi S. (2005) Institutions of Governance, Power Diffusion and Pro-Poor Growth Policies. Paper presented at the VII Senior Policy Seminar organized by AERC, Cape Town Johannesburg, South Africa, March.

Klasen, S. (2002) In Search of the Holy Grail: How to Achieve Pro-Poor Growth? Paper Commissioned by GTZ, University of Munich.

Kraay, A. (2004) When is Growth Pro-Poor? Cross-country Evidence. Washington, DC, World Bank. (World Bank Policy Research Working Paper 3225).

La Porta, R., E Lopez de Silanes and A. Shleifer: 1999, 'Corporate Ownership Around the World', The Journal of Finance 54(2), 471-517.

Lang, L. H., \& Stulz, R. M. (2013). Tobin's q, corporate diversification and firm performance (No. w4376). National Bureau of Economic Research.

Lopez, J. H. (2004b) Pro-growth, Pro-poor: Is there a Tradeoff? World Bank, Washington, DC. (World Bank Policy Research Working Paper 3378).

Mahbubul Haq Human Development Centre (1999) Human Development in South Asia, The Crisis of Governance. Mahbubul Haq Human Development Centre and the Oxford University Press, Pakistan.

McCawley Peter (2005) Governance in Indonesia: Some Comments. Tokyo. (ADBI Research Policy Brief No.17).

McCulloch, Neil, and B. Baulch (1999) Assessing the Poverty Bias of Economic Growth: Methodology and Application to Andhra Pradesh. Institute of Development Studies, Brighton. (Working Paper No. 98.)

Moore, M., J. Leavy, P. Houtzager, and H. White (1999) Polity Qualities: How Governance Affects

Pasha, Hafiz A. (2000) Elements of Good Economic Governance. Social Policy Development Centre. (Research Report No. 30).

Ravallion, M. and S. Chen (2003) Measuring Pro-Poor Growth. Economic Letters 78,

Resnick and Regina Birner (2006) Does Good Governance Contribute to Pro-Poor Growth? A Review of the Evidence from Cross-Country Studies. International Food Policy Research Institute.

Social Policy and Development Centre (2005-06) Social Development in Pakistan. Annual Review. Karachi.

Son, Hyun Hwna (2004) A Note on Measuring Pro-Poor Growth. Economic Letters 82, Statement by the DAC High level Meeting, April 25-26, OECD. Paris, France. Pakistan, Government of (20052006) Pakistan Economic Survey. Islamabad: Ministry of Finance.

Stewart, B: 1992, 'The Role of Corporate Boards in the 1990s', in D. Chew (ed.), The New Corporate Finance: Where Theory Meets Practice (Blackwell, New York).

Stewart, T. L: 1993, 'The King is Dead', Fortune 127(1) (January 11), 34-48.

UNDP (1997) Governance for Sustainable Human Development. New York: Management and Governance Division, Bureau for Policy and Programme Support. United Nations (2000) A Better World for All. New York: United Nations.

White, H. and E. Anderson (2001) Growth versus Distribution: Does the Pattern of Growth Matter? Development Policy Review 19:3,267-289.

World Bank (2005a, 2005b) Governance Indicators: 1996-2004. Washington, DC: World Bank. 